\title{
Health research in Africa: Are we communicating our findings to relevant stakeholders? \\ Ifeoma N. Onyeka
}

Institute of Public Health and Clinical Nutrition, Faculty of Health Sciences, University of Eastern Finland, Kuopio. P.O.Box 1627, Kuopio 70211, Finland. E-mail: ifeoma.onyeka@uef.fi

\section{DOI: http://dx.doi.org/10.4314/ahs.v14i3.43}

There is increasing awareness of research and innovation across Africa. Each year, researchers in universities and research institutes generate new knowledge and ideas. However, it is doubtful if there is an information flow to those outside academia. This feature holds true in many countries across the world; Africa, however, is unique in that many countries within it suffer from this lack ofinformation flow.

This commentary discusses the need to communicate research findings to

relevant stakeholders in order to improve people's health.

Stakeholders include other researchers who may build on research findings, and persons who may benefit from them, who may use them

and who may have a stake in them1. Also included are persons who pay for, deliver or fund health programmes.

Findings from African research studies are often published in peer-reviewed scientific journals, presented in scientific conferences, seminars and workshops in Africa and other parts of the world.

Sharing findings with researchers and other members of the scientific community helps to increase their knowledge of new research methods and findings and improve their scientific skills. Another important advantage is to avoid overlap of efforts - duplicating studies within the same location or a similar location may not add further value to knowledge and may amount to wastage of scarce research resources.

Presenting findings to the scientific community increases visibility for the researcher, the research findings, and the research institutes concerned and may lead to advancement in a researcher's rank 2 or position. However, non-scientists or scientists in other fields may be unaware of these peer-reviewed journals, where the full research reports are published. Even when they are aware, journal subscription fees may further limit their access to journal articles.

To solve this problem, BioMed Central2, Bioline Inter- national3, Public Library of Science (PLOS) 4 and other open access publishers offer free online access to research studies conducted in different parts of the world including Africa.

Free or low cost access to journal articles and other electronic literature is also available through the Health Inter Network Access to Research Initiative (HINARI)5, Directory of Open Access Journals (DOAJ)6, and African Journal Online (AJOL) 7, among others.

Some research findings have practical implications for health professionals. Due to their busy schedules, they do not have enough time to search for new research information.

Researchers could communicate their findings to health professionals through their professional associations, meetings, and conferences, among others. Appropriate details should be provided by researchers to help them decide on the effectiveness of a research finding in relation to practice and delivery of care1.

Health professionals and scientists, although busy, could update their knowledge by availing themselves of the services of librarians, who are skilled at information retrieval, to assist with literature search.

Policy makers are important stakeholders who could also use research findings and can implement study recommendations.

They could be government policy makers, heads of health institutions, heads of schools or some other organisation. Communicating research findings with policy implications will provide policy makers with valuable information for evidence-based decision making 1. Such information could be communicated as short reports or policy papers, followed by a meeting where policy makers would have the opportunity to ask questions and seek clarification.

It is mandatory that use of technical terms and complex statistical data be avoided. Instead, it is recommended that researchers adopt a problem-solution approach, whereby they outline possible ways of solving a health problem and present strong arguments to support policy recommendations 
based on their study findings8. Of course, findings from a single study are inadequate for policy formulation but they may inform future research directions to gather more evidence and can motivate policy makers to fund future research activities.

Where possible, key policy makers and key decision makers should undergo training focused on knowledge translation. For example, some participants in a Canadian study 9 reported that training programmes helped to educate them in the use of research evidence in decision making.

Members of the general public are important beneficiaries of research findings because many studies are funded with taxpayers' money.

Communicating health-related research findings to the general public is part of researchers' social responsibility; it ensures that taxpayers get good value for their money and that community members who participated in the study are rewarded for their time 10. It also helps to create awareness about health and health conditions, foster acceptance of science and may attract potential research partners and funding sources8. Television, newspapers, radio, press release, public meetings and workshops are some of the avenues for communicating research findings to the general public.

There could be more stakeholders other than those mentioned above - the list varies by type of research study or health problem under investigation. Stakeholder analysis could help researchers to identify the target audience.

Ideally, planning on how to communicate research findings should take

place at the initial phase of the study 11 . After researchers identify the relevant stakeholders, they communicate their research findings to this group after these findings have been published in peer-reviewed journals in Africa or elsewhere.

Due to the extremely long peer-review process in some journals, such communication could be done earlier if the research findings require urgent attention.

Even if stakeholder analysis is not done at the initial stage, it is still pertinent to get research findings across to relevant stakeholders. Depending on the nature of the research study, stakeholder involvement may be more than mere dissemination of study results 12 ; for example, it could involve a call to action.
To increase the effectiveness of communicating healthrelated research results, the message should be appropriately tailored to the target audience.

Use of highly technical terms is appropriate when communicating to other researchers but not for nonresearchers or the general public because they have different levels of education, health knowledge and health motivation.

Apart from increasing comprehension, communicating research findings in an understandable manner will persuade the audience to interpret health information as being personally relevant, increase the impact on individual thought and help to change attitudes and health behaviours 13 .

It has been suggested that research projects should have a communication and dissemination team (possibly with professional communication specialists) to increase the potential impact of their research 14. Collaboration between researchers and journalists fosters media engagement. As reported in Zambia 15, such partnership helped to increase the accuracy and quality of health reporting.

When presenting results, it is imperative that researchers give careful consideration to how the target audience could translate them into action: researchers should give specific examples of what could be done to improve people's health. For example "brisk walking for 30 minutes or more a day, at least three times per week" is more specific than "moderate-level physical activity per week." A meta-analytic review by Gallagher and Updegraff 16found that framing a health message to emphasise the benefit of a particular behaviour helped to promote illness prevention behaviour

such as smoking cessation, skin cancer prevention and physical activity.

In summary, results from health research should go beyond "information by researchers for other researchers". Unless such knowledge and ideas are communicated to relevant stakeholders in health/healthcare and put into action, they may not translate into improvements in people's health and policy makers may not have information necessary for evidence-based decision making 17.

Health communication skills could be acquired through practice or via formal training or by using resources freely available on the Internet. We need to understand 
that communicating research findings to relevant stakeholders is something we can and should do to tackle various public health problems facing the African continent.

Ifeoma N. Onyeka,

Finland, Kuopio. P.O.Box 1627, Kuopio 70211, Finland. E-mail: ifeoma.onyeka@uef.fi

\section{References}

1. Fathalla MF, Fathalla MFF. A practical guide for health researchers: Communicating research. [internet]. 2004.http://applications.emro.who.int/dsaf/dsa237. pdf. Accessed 28 August 2012.

2. BioMed Central. [internet] . 2013. http://www.biomedcentral.com/ .Accessed 07 June 2013.

3. Bioline International. [internet]. 2013. http://www. bioline.org.br/ .Accessed 07 June 2013.

4. Public Library of Science (PLOS). [internet]. 2013. http://www.plos.org/ . Accessed 07 June 2013.

5. Health Inter Network Access to Research Initiative (HINARI). [internet]. 2013. http://www.who.int/hinari/en/ . Accessed 07 June 2

013.

6. Directory of Open Access Journals (DOAJ). [internet]. 2013. http://www.doaj.org/ . Accessed 07 June 2013

7. African Journal Online (AJOL). [internet]. 2013. http://www.ajol.info/ . Accessed 07 June 2013.

8. Addison C. Communicating research: More than a need, a necessity.

[internet]. 2009 http://www.ddrn.dk/filer/forum/ File/communicating_r esearch_final_reader.pdf. Accessed 28 August 2012.
9. Ellen ME, Lavis JN, Ouimet M, Grimshaw J, Bédard PO. Determining research knowledge infrastracture for healthcare systems: A qualitative study. Implement Sci 2011; 6:60.

10. Unite for sight. The importance of submitting data to the local community.[internet]. 2012. http://www. uniteforsight.org/global-health-university/research-local-community. Accessed 14 September 2012.

11. MEASURE Evaluation. Making research findings actionable: A quick reference to communicating health information for decision-making. [internet]. 2012. http://www.cpc.unc.edu/measure/publications/ms09-39

. Accessed 28 August 2012.

12. The Population and Poverty Research Network. Involving Stakeholders in your research project. [internet]. 2012. http://www.poppov.org/Portals/1/documents/ events/RFP/involving-stakeholders.pdf. Accessed 30 August 2012.

13. Wilson BJ. Designing media messages about health and nutrition: What strategies are most effective? J Nutr Educ Behav2007; 39: S13 - S19.

14. European Commission. Communicating research forevidence-based policymaking: A practical guide for researchers in socio-economic sciences and humanities. Luxembourg: Publications Office of the European Union; 2010, 56 pp.

15. Yngstrom I. Reporting health research: Connecting journalists and TB researchers in Zambia. London: Panos London; 2011, 16 pp.

16. Gallagher KM, Updegraff JA. Health message framing effects on attitudes, intentions, and behavior: A meta-analytic review. Ann Behav Med2012; 43:101 $-116$.

17. Graham ID, Tetroe J. CIHR research: How to translate health research knowledge into effective healthcare action. Healthc Q 2007; 10 (3): 20 -22. 